\title{
Tentativas jurídicas de legitimación del proyecto pizarrista en Perú (1544-1548)
}

\author{
Ana Laura Drigo \\ Universidad de Buenos Aires, Argentina \\ drigo_ana@yahoo.com.ar
}

\begin{abstract}
Resumen
El análisis de la rebelión de Gonzalo Pizarro deja entrever una sociedad hispanoperuana víctima de profundas transformaciones sociopolíticas, al destacar las disputas entre concepciones, valores y formas de entender la realidad política y jurídica que iban a destiempo respecto de los cambios producidos en la Metrópoli. El estudio de los argumentos jurídicos implementados por el movimiento pizarrista para legitimar su empresa deja al descubierto la pugna entre dos modelos políticos, al apelar a antiguos derechos feudales que consideraban legítimos, aunque ya no fueran legales en el marco del naciente Absolutismo. De esta manera, la rebelión muestra la pervivencia, tanto en gran parte de la población como en el aparato jurídico, de paradigmas propios de la baja Edad Media e indica que solo recientemente, y de forma embrionaria, comenzaban a perfilarse en América los primeros indicios de la Modernidad.
\end{abstract}

Palabras clave: GONZALO PIZARRO, PERÚ, SIGLO XVI, REBELIONES, ABSOLUTISMO.

\begin{abstract}
The analysis of Gonzalo Pizarro's rebellion hints at a Hispanic Peruvian society that falls in deep social and political transformations when emphasising the disputes over the conceptions, the values and the ways of understanding the political and legal reality that did not coincide with the changes produced in the metropolis. Thus, the study of the legal arguments implemented by the Pizarrist movement to legitimate its enterprise shows us the clash between two political models when resorting to old feudal rights which were considered legitimate although they were not in the framework of the incipient absolutism. In this way, the rebellion illustrates, both in a large part of the population and in the legal system, the coexistence of paradigms typical of the Late Middle Ages indicating that only recently and in an embryonic way, the first signs of modernity began to appear in America.
\end{abstract}

Key words: GONZALO PIZARRO, PERÚ, 16TH CENTURY, REBELLION, ABSOLUTISM. 
"Era un mundo en el que se confundían, latiendo juntos, presente, pasado y porvenir"1.

Este trabajo tiene como objetivo analizar las tentativas jurídicas utilizadas por el movimiento pizarrista para legitimar la gran rebelión de Gonzalo Pizarro (15441548). La misma se inserta dentro del llamado Período de Guerras Civiles que acosó al Perú durante la primera mitad del siglo XVI y muestra los primeros desafíos a la autoridad real por parte de los colonizadores españoles. Estos últimos apelaban a lo capitulado con la Corona al tiempo que reclamaban los derechos ganados en la tarea de conquista y colonización de estos reinos frente a las medidas reales plasmadas en las Leyes Nuevas y tendientes a cercenar el poder de los mismos.

La rebelión de Gonzalo Pizarro ha sido tema de muchos y variados análisis históricos. Así, encontramos en la historiografía trabajos clásicos, como los de Rosa Arciniega y Juan Pérez de Tudela Bueso ${ }^{2}$, que realizan un interesante análisis de la rebelión -aunque desde perspectivas diferentes- a partir de las crónicas de la época. La primera propone un análisis de Gonzalo Pizarro más descriptivo y resalta los atributos del líder rebelde, mientras el segundo analiza el período de guerras civiles dejando entrever claramente su discrepancia con esta rebelión que desafió a la autoridad real. También se destaca el trabajo de James Lockhart ${ }^{3}$, que permite reconstruir las redes de poder del linaje pizarrista y destaca la importancia que tuvo entre estos primeros conquistadores la agrupación por facciones para acceder y reforzar su poder en América. Esto último es retomado y desarrollado por Rafael Varón $\mathrm{Gabai}^{4}$, quien desde un enfoque más económico resalta las estrategias pizarristas para acrecentar el patrimonio familiar. A su vez, es preciso destacar el trabajo de Ana María Lorandi ${ }^{5}$, con interpretaciones alternativas para estudiar la rebelión dentro del conflictivo contexto sociopolítico que brinda la sociedad hispanoperuana del siglo XVI. Así, reconoce el estado de profunda confusión de los actores sociales, que oscilaban entre dos lógicas políticas: el interés privado y la necesidad de defender sus intereses, por un lado, y el respeto a la autoridad real, a las normas y a los principios éticos de la época, por el otro.

\footnotetext{
${ }^{1}$ José Durand, La transformación social del conquistador (Lima: Nuevos Rumbos, 1958).

${ }^{2}$ Rosa Arciniega, Dos rebeldes españoles en el Perú. Gonzalo Pizarro y Lope de Aguirre (Buenos Aires: Sudamericana, 1946); Juan Pérez de Tudela Bueso, "Observaciones generales sobre las guerras civiles del Perú", en Crónicas del Perú, Serie Biblioteca de Autores Españoles, t. 164 (Madrid: Atlas, 1963).

3 James Lockhart, Los de Cajamarca. Un estudio social y biográfico de los primeros conquistadores del Perú, 2 t. (Lima: Milla Batres, 1986).

${ }^{4}$ Rafael Varón Gabai, La ilusión de poder. Apogeo y decadencia de los Pizarro en la conquista del Perú (Perú: IEP; IFEA, 1996).

${ }^{5}$ Ana María Lorandi, Ni ley, ni rey ni hombre virtuoso. Guerra y sociedad en el virreinato del Perú. Siglos XVI y XVII (Barcelona: Gedisa, 2002).
} 
Por su parte, Lohmann Villena ${ }^{6}$ realizó un interesante estudio sobre las ideas jurídico-políticas de la rebelión pizarrista donde destaca los recursos legales utilizados por los rebeldes para justificar su accionar frente a la Corona. Podemos decir que predomina en su trabajo una perspectiva metropolitana en el estudio de la situación americana. Acá tomamos su trabajo como punto de partida, pero proponemos ir más allá, teniendo como eje los discursos de los propios actores involucrados en estos conflictos. Proponemos aquí cambiar el ángulo de visión con el fin de centrar estas demandas dentro de la propia perspectiva de los sujetos que llevaron a cabo esta rebelión. Como bien plantea Pietschmann ${ }^{7}$, es preciso descentralizar el enfoque que ve la relación entre la Corona y sus colonias americanas como una relación unilateral donde solo se pondera la perspectiva imperial. Este punto de vista cobra relevancia en los últimos años y promueve estudios que destaquen las respuestas encaradas por la propia sociedad americana a las imposiciones reales, y es allí donde nuestro análisis cobra relevancia.

Cabe destacar que la totalidad de los temas aquí trabajados no deben dejar de mirarse bajo una óptica mayor que abarque la complejidad de los acontecimientos que afectaban a la sociedad peruana del siglo XVI. Nuestra contribución consistirá, entonces, en profundizar y apoyar con documentos la idea que sostiene que la sociedad que se gestaba en estos nuevos territorios estaba inmersa en un contexto de transición cuyos actores sociales eran también sujetos en transición, al ser partícipes de un modelo que estaba cambiando. Así, es necesario tener siempre presente las disputas entre concepciones, ideas y valores nuevos y viejos. Es en esta perspectiva donde el accionar y los argumentos legales apelados por los conquistadores cobran sentido.

$\mathrm{Al}$ analizar los argumentos utilizados por Gonzalo Pizarro y su movimiento para enfrentar la autoridad real, no queremos caer en simples generalizaciones y formular las bases de una mentalidad colectiva para toda la sociedad peruana (sobre todo considerando su gran heterogeneidad), pero sí podemos destacar la presencia de cierto patrón entre los conquistadores y encomenderos, quienes operaban desde representaciones medievales a la hora de defender con uñas y dientes las recompensas de la conquista, apelando para ello a su pacto con la Corona.

\footnotetext{
${ }^{6}$ Guillermo Lohmann Villena, Las ideas jurídico politicas en la rebelión de Gonzalo Pizarro. La tramoya doctrinal del levantamiento contra las Leyes Nuevas en el Perú (Valladolid: Casa-Museo de Colón y Seminario Americanista; Universidad de Valladolid, 1977).

${ }^{7}$ Horst Pietschmann, "Los principios rectores de organización estatal en las Indias", en Inventando la Nación. Iberoamérica. Siglo XIX, A. Annino y François-Xavier Guerra (México: Fondo de Cultura Económica, 2003).
} 
La defensa intelectual llevada a cabo por los consejeros del movimiento pizarrista nos permite observar la permanencia en estos territorios de cierta lógica que se relaciona con la dinámica de poder de la sociedad bajomedieval española que opera como contexto en las prácticas llevadas a cabo por los conquistadores en el Perú, en contraposición con el naciente absolutismo monárquico que se gestaba en la Metrópoli. En esta línea de análisis, proponemos un enfoque que pondere la propia perspectiva de los conquistadores y encomenderos dentro del marco de transformaciones ideológicas y políticas que brindaba la sociedad colonial y que se expresaron, al mismo tiempo, en el ámbito jurídico.

Los documentos utilizados para trabajar estos temas consistieron en crónicas de diversos autores de la época ${ }^{8}$ y cartas privadas ${ }^{9}$ que conectaron a Gonzalo Pizarro con los principales hombres de su movimiento y con las autoridades reales, lo que nos permite observar los argumentos utilizados para avalar la rebelión. A través de la lectura de las fuentes se percibe a los encomenderos como personas que entendían la realidad política de diversas maneras, por vivir en una sociedad en constante construcción y transformación. De esta manera, los argumentos del movimiento pizarrista ponen de manifiesto que tanto líder como seguidores se hallaban convencidos de la legitimidad de sus actos y los consideraban lícitos bajo las formas jurídicas vigentes, pero que, sin embargo, ya no tenían fuerza legal dentro del marco del naciente absolutismo monárquico.

\section{Demandas y reclamos al rey contra las Leyes Nuevas}

Como se ha dicho anteriormente, cuando Gonzalo Pizarro encabezaba su rebelión, el modelo castellano medieval permanecía vigente en un sector importante de la sociedad peruana, en oposición al naciente absolutismo promovido por la Corona.

\footnotetext{
${ }^{8}$ Entre los cronistas analizados se encuentran Pedro Cieza de León, Crónica del Perú ([1553]; Lima: Pontificia Universidad Católica del Perú, 1991-1994), vol. 3, t. 2, parte 4; Agustín de Zárate, Historia del descubrimiento y conquista del Perú, edición, notas y estudio preliminar de Franklin Pesase G. Y. y Teodoro Hampe Martínez ([1555]; Lima: Pontificia Universidad Católica del Perú, 1995); Juan Pérez de Tudela Bueso, Crónicas del Perú, vol. 1, Primera y segunda parte de la Historia del Perú que se mandó a escribir a Diego Fernández, vecino de Palencia, Serie Biblioteca de Autores Españoles, t. 164-168 ([1568]; Madrid: Atlas, 1963); Pedro Gutiérrez de Santa Clara, "Quinquenarios o Historia de las guerras civiles del Perú", en Pérez de Tudela, Crónicas del Perú, t. 164; e Inca Garcilaso de la Vega, Historia General del Perú. Segunda parte de los comentarios reales de los Incas ([1617]; Buenos Aires: Emecé, 1944), entre otros.

9 Juan Pérez de Tudela Bueso, ed., Documentos relativos a Don Pedro de La Gasca y a Gonzalo Pizarro (Madrid: Archivo Documental Español; Real Academia de la Historia, 1964), t. 21, vols. 1-2.
} 
En esta coyuntura, Pizarro y los ideólogos de su movimiento ${ }^{10}$ construyen una serie de postulados que pretendían avalar la gobernación del líder rebelde.

Lohmann Villena ${ }^{11}$ analiza este tema con una profunda minuciosidad y así entiende que los planteos jurídicos de los pizarristas se correspondían con corrientes y concepciones ya marchitas en España. Según dicho autor, toda situación, de hecho anhela establecerse bajo formas de derecho y tiende a regularizar, por medio de una ficción jurídica, la ilegitimidad de origen. Así, para el autor, la rebelión de Gonzalo Pizarro se deslizó hacia un área muy alejada del Estado de derecho para concluir en una actitud de oposición a la autoridad oficial. Al mismo tiempo, considera que todos los procedimientos llevados a cabo adolecían del vicio de ilegitimidad, ya que Pizarro se había propasado en sus atribuciones, y agrega que los insurrectos habían intentado consolidar jurídicamente una posición invulnerable para el líder rebelde. En otras palabras, se trataba de borrar todo rasgo de desobediencia intentando cubrir con una máscara legal los oscuros manejos del pizarrismo. De esta manera, los fundamentos rebeldes se articulaban, según el mencionado autor, con doctrinas y conceptos ya caídos en desuso para ese entonces en la península.

Para Lohmann Villena, los ideólogos del movimiento pizarrista supieron apropiarse de vetustos principios y amoldarlos así al contexto peruano. Tomando estos planteos como base de nuestro análisis, cabe agregar que la lectura de las cartas privadas de Gonzalo Pizarro y sus seguidores revela un profundo convencimiento en las prácticas jurídicas llevadas a cabo por los pizarristas, demostrando el fuerte arraigo de tales principios en la conciencia jurídica y política de los españoles residentes en esta parte de América. Como dice Annick Lempérière:

No solo los vasallos americanos, al igual que los súbditos de las distintas monarquías europeas, utilizaron a finales del Antiguo Régimen los recursos más tradicionales y comprobados de representación a modo de resistencia [...] a la ofensiva administrativa del absolutismo ${ }^{12}$.

${ }^{10}$ Entre los asesores jurídicos se destacan: el Lic. Vázquez de Cepeda, Lic. León, el Bachiller Vélez de Guevara, los Lic. Barba, De la Gama, Benito Suárez de Carvajal (teniente de gobernador de Pizarro en 1535 y hermano del doctor Suárez de Carvajal, obispo de Lugo y consejero de Indias), Lohmann, Las ideas jurídico políticas.

${ }^{11}$ Ibídem.

12 Annick Lempérière, "La representación política en el Imperio Español a finales del Antiguo Régimen", en Dinámicas de Antiguo Régimen y orden constitucional. Representación, justicia y administración en Iberoamérica. Siglos XVIII-XIX, coord. Marco Bellingeri (Turín: Otto Editore, 2000), 57. 
Para demostrar la pertinencia de este aserto en nuestro caso, una de las principales fuentes en la que basaremos nuestro análisis es la "Representación de Gonzalo Pizarro al rey"13. En la misma se despliegan las razones que justificaban enmendar y abolir las ordenanzas de las Leyes Nuevas más perjudiciales para los encomenderos y funcionarios del Perú. Haremos un recorrido por las demandas de Gonzalo Pizarro y su gente para poder así comprender este tema desde su propia perspectiva.

El derecho a reclamar contra las leyes que más perjudicaban al bien común se remonta a la tradición escolástica, la cual reconocía que "la ley pierde su fuerza obligante cuando se aparta de su objetivo esencial: el bien común"14. Basándose en principios del derecho natural, el rey no podía dictar leyes que perjudicaran a sus vasallos ni estos debían renunciar a reclamarlas. Este contrato entre el rey y sus súbditos es un principio con claras raíces medievales en el que se desconocía la naciente noción que sustentaba el absolutismo monárquico, por la cual el rey estaba facultado para "imponer, enmendar y derogar leyes [...] sin limitación ni condicionalidad"15. Cabe destacar que en el período bajomedieval existían dos concepciones en pugna. Como bien expone Monsalvo Antón ${ }^{16}$, por un lado, el poder nacía de un pacto entre rey y súbditos. Era un poder compartido, con dos polos, rey y reino, en el que el rey tenía los límites de la ley y el pacto. Se trataba de una relación "contractual", también llamada "pactista". Por otro lado, se entendía que el origen divino del poder recaía inmediatamente en el rey, lo cual ejemplificaba la solución del autoritarismo real. Aún así, el antiguo pacto entre el rey y el pueblo, sustentado por las Siete Partidas de Alfonso X, habría de permitir que la fórmula "Se acata, pero no se cumple" permitiera apelar una y otra vez las decisiones del rey. Ninguna resolución real era aceptable si perjudicaba los intereses de sus súbditos.

Respecto de esta cuestión, es preciso destacar que, aunque el principio del contrato medieval había comenzado a perder vigencia, el derecho a reclamar y a oponerse a distintos decretos u ordenanzas reales que fueran en contra de la voluntad popular siguió ejerciéndose en América hasta bien entrado el siglo XVIII, incluso durante la dinastía borbónica, que acrecentó las medidas del control monárquico ${ }^{17}$. Para el siglo XVI que estamos analizando, permanentemente encontramos en los argumentos jurídicos de los rebeldes principios de raigambre medieval en donde se apelaba a este contrato entre rey y vasallos. De esta manera, nuestro propósito consiste en demostrar que estas concepciones continuaron vigentes tanto en la

\footnotetext{
${ }^{13}$ Pérez de Tudela, Documentos relativos, 2: 383-395.

${ }^{14}$ Lohmann, Las ideas jurídico políticas, 39.

${ }^{15}$ Ibídem, 40-41.

16 José María Monsalvo Antón, La baja Edad Media en los siglos XIV-XV. Política y cultura (España: Síntesis, 2000), caps. 3 y 7.

${ }^{17}$ Lorandi, Ni ley, ni rey.
} 
legislación como en el imaginario de la población y, por lo tanto, era de esperarse que recurrieran a ellas para defender los derechos que creían justos.

Para comprender sus fundamentos en la defensa de sus intereses que se veían afectados por las Leyes Nuevas, partiremos de las demandas que hacía el propio Gonzalo Pizarro al respecto. Con una fuerte defensa de sus intereses y de quienes representa, pide la revocación de la Ley 26, que exigía poner en manos de la Corona aquellos indios que se encontraran en poder de los gobernadores, oficiales de la hacienda real, clérigos y oficiales de justicia, y apela a las promesas del rey de recompensar con indios a quienes habían conquistado estas tierras.

Siendo como es la dicha ordenanza tan en perjuicio destos dichos reinos e de los que han tenido los dichos oficios, e tan intolerable como es notorio, la cual vuestra alteza debe enmendar y revocar en todo [...] porque mucho de los tales oficiales e lugares tenientes de gobernador y gobernador, son de los dichos conquistadores que con dicho gobernador y marqués don Francisco Pizarro vinieron debajo de la esperanza e promesa que vuestra alteza les hizo, que fue que los indios que en esta tierra se conquistasen se repartiesen entre ellos, por lo cual en la dicha conquista gastaron sus haciendas e patrimonios, e si supieron que por ser tenientes e tener oficios de vuestra alteza les habían de quitar sus repartimientos, no los tomaran ni usaran dellos por ninguna vía, y es cosa muy absurda y contra derecho que ninguno pague ni sea penado por aquello que no sabía ser pecado o delito, cuanto más que nuestra alteza no puede de derecho hacer ni promulgar ley que ponga pena en lo pasado que no era delito, ni contra buenas costumbres, ni prohibido en derecho, ni tales leyes penales se pueden entender ni extender en lo pasado [...] porque es cosa fea que vuestra alteza haga merced en que parece recibir servicio, para que haciéndolo vuestro vasallo e las personas a quien se hizo, por ello les quiten sus faciendas e lo que han ganado con la lanza en la mano, con mucho trabajo e gasto e riesgo de sus personas ${ }^{18}$.

Continúa diciendo:

[...] vuestra alteza va contra lo capitulado con el dicho gobernador y marqués, hasta tanto que sean satisfechos e remunerados los que debajo dellos vinieron a conquistar e poblar estos reinos [...] la cual ordenanza debe vuestra alteza guardar e suspender hasta que estén satisfechos los que han trabajado e servido en estos reinos $[\ldots]^{19}$.

\footnotetext{
${ }^{18}$ Pérez de Tudela, Documentos relativos, 2: 387. Énfasis agregado.

${ }^{19}$ Ibídem, 2: 388. Énfasis agregado.
} 
Como podemos ver, esta es una pieza jurídica impecable en términos de la concepción pactista. Su argumentación permite remontarnos a la Capitulación de Toledo firmada en 1529 entre Francisco Pizarro y la Corona ${ }^{20}$, en la cual el conquistador, además de haber sido recompensado con importantes mercedes económicas y honoríficas por sus labores de conquista, fue facultado para otorgar encomiendas de indios en recompensa a aquellos hombres que le habían servido. De esta manera, Gonzalo, en nombre suyo y "de los vecinos, conquistadores e pobladores destos reinos", reprocha a la Corona quebrantar el pacto establecido que implicaba para los conquistadores un fuerte agravio sobre lo convenido con ellos. Así, los rebeldes sostenían: "Vuestra alteza ha de cumplir su promesa e merced que les hizo, a lo cual está obligado naturalmente, pues aquel fue contrato obligatorio entre vuestra alteza y los tales conquistadores" ${ }^{21}$.

Como se sabe, en las capitulaciones la Corona mantenía el dominio sobre los territorios descubiertos y, a cambio de ello, quienes habían participado en la conquista y descubrimientos eran beneficiados con mercedes, encomiendas de indios o cargos públicos. Así, debido a la financiación y el riesgo personal invertido, los conquistadores no estaban dispuestos a renunciar a la explotación económica de sus indios encomendados; sin duda, este era el premio más importante por el cual atravesaron el océano en busca de riquezas y prestigio social. Este es un indicativo, entre otros, de la permanencia de una mentalidad señorial en América, que, lejos de caer en desuso, se acrecentó en esta parte del mundo ${ }^{22}$.

Bajo el mencionado esquema, una por una, va apelando por la revocación de las leyes que más los perjudican, enfrentándose con fuertes fundamentos y sin medias tintas, por ir contra las propias provisiones reales. Sobre la ley que castigaba con sacarle los indios a quienes habían intervenido en las guerras civiles entre Pizarro y Almagro, Gonzalo expone:

Vuestra alteza debe mandar la dicha ordenanza que se enmiende y entienda, en los que hobieren cometido delito alguno en las dichas rebelaciones e pasiones, a los cuales castiguen conforme a derecho, pues esto es justicia, y vuestra alteza no es razón que los castigue mas regurosamente que el derecho manda ${ }^{23}$.

${ }^{20}$ La capitulación entre Pizarro y la Corona se encuentra editada por Raúl Porras Barrenechea, Cedulario del Perú. Siglos XVI, XVI y XVIII (Lima: Ministerio de Relaciones Exteriores del Perú, 1944).

${ }^{21}$ Ibídem, 391. Énfasis agregado.

${ }^{22}$ Lorandi, Ni ley, ni rey.

${ }^{23}$ Porras, Cedulario del Perú, 388. Énfasis agregado. 
En cuanto a la Ley 30, se explaya en sus argumentos y hace desafiantes acusaciones sobre los deberes del rey, pues ella impedía a los primogénitos varones legítimos heredar la encomienda de indios de su progenitor y fue una de las medidas que más ira provocó entre los conquistadores ${ }^{24}$. En su exposición presenta sus razones para la revocación de las leyes más ofensivas a los intereses de los conquistadores y encomenderos. Pide su revocación, porque

Ello va contra lo que ha prometido y está obligado a cumplir naturalmente. [...] Habiendo cumplido de nuestra parte los que ansí habemos venido a hacer lo susodicho, vuestra alteza debe cumplir de la suya la promesa que nos hizo, $[\ldots]$ por ser como es obligación natural, o al menos de derecho de las gentes que a vuestra alteza obligan a los cumplir, y en ello no puede disponer ni quitar, $[\ldots]$ yendo como vuestra alteza va contra vuestro hecho público e palabra real que vuestra alteza nos es obligado a guardar e cumplir $^{25}$.

De esta manera, sostiene:

Habiendo cumplido de su parte, e para ello gastado e desipado sus haciendas e patrimonios que en España tenían para venir a estas partes con la dicha esperanza que vuestra alteza con ellos cumpliera [...] Y no se debe decir por un príncipe tan justo e cristiano como vuestra alteza es, que hace fraude ni elusión alguna a sus vasallos ni criados, e que no les guarda su palabra real e promesa siendo a ello obligado naturalmente no pudiéndolo hacer de derecho, en lo cual, si vuestra alteza mirara, no solamente no proveyera la dicha ordenanza, pero castigara a quien tal le aconsejó. [...] porque la conquista y descubrimiento destos reinos no se hizo a costa alguna de vuestra alteza ni en ello gastó cosa alguna $[\ldots]^{26}$.

Vale la pena aclarar aquí que, en 1533, la emperatriz Isabel pronunció la intención de entregar a perpetuidad los repartimientos de indios a aquellos conquistadores que quisiesen quedarse en la tierra, reservando algunos de ellos para la propia Corona. Así, se establecía que Francisco Pizarro tendría el control de la distribución de los mismos y podía reforzar así su estructura de poder ${ }^{27}$.

\footnotetext{
${ }^{24}$ Recordemos que la sucesión de la encomienda por dos vidas se había decretado en 1536 por medio de una real provisión y que en 1704 se prorrogó por una cuarta vida el disfrute de encomiendas mediante el pago de dos annatas para los gastos de guerra. J. M. Ots Capdequí, El Estado español en las Indias (México: Fondo de Cultura Económica, 1975).

${ }^{25}$ Pérez de Tudela, Documentos relativos, 2: 389. Énfasis agregado.

${ }^{26}$ Ibídem. Énfasis agregado.

${ }^{27}$ Varón, La ilusión de poder.
} 
Queda claramente planteado aquí la indignación que producía la violación de la palabra real y cuánto afectaba esto a los intereses de los encomenderos y primeros conquistadores. Debido a la riqueza de información que el documento posee y la pasión que Gonzalo pone en cada una de sus palabras, se hace difícil omitir ciertos párrafos de su representación. Así, manifiesta en sus alegatos que:

De derecho, la merced que el príncipe hace, no la puede revocar por ninguna vía después de hecha, por lo cual la dicha ley y ordenanza debe ser por vuestra alteza enmendada e revocada en todo e por todo e así se lo suplico $^{28}$.

De esta manera, se destaca el valor que tenía para los conquistadores la palabra real plasmada en las capitulaciones y que la Corona parecía quebrantar. Asimismo, vemos a los pizarristas apelar al derecho natural, uno de cuyos primordiales principios es la legítima defensa contra la injusticia; es decir, el soberano no puede dictar leyes que perjudiquen a sus vasallos y estos no deben dejar de reclamar por lo que creen justo. La convicción que se observa en cada uno de sus argumentos es clara y se deja entrever en las cartas analizadas. Un ejemplo de ello es esta carta que los principales del Perú ${ }^{29}$ escribieron a La Gasca: "Porque perdón ninguno de nosotros le pide, porque no entendemos que hemos errado, sino servido a $\mathrm{Su}$ Majestad, conservando nuestro derecho que por sus leyes reales a vasallos es permitido, ${ }^{, 30}$.

Esta acción de interpelar en función de restablecer el orden alterado responde a un deber moral y político. A su vez, los rebeldes reconocían en el derecho vigente el recurso a la guerra, en caso de que no existiera otra alternativa para hacer valer sus demandas. Así, recurriendo a leyes de las Siete Partidas y al derecho natural, los peruleros encontraron un escudo legal con el cual defender su derecho a la resistencia. Estos, en su afán de salvaguardar lo que creían legítimo, proclamaban el derecho inalienable de los vasallos a ser escuchados antes de la aplicación de leyes perjudiciales para ellos, ya que, según afirmaban, "esto es conforme a derecho"31:

Nosotros no queremos batalla [...] Nosotros no pedimos sino justicia, [...] no deseamos sino lo que Su Majestad quiere y desea, que es oírnos y que

\footnotetext{
${ }^{28}$ Pérez de Tudela, Documentos relativos, 2: 391. Énfasis agregado.

29 Entre los principales del Perú se encuentran: Lic. Carvajal, Bachicao, Lic. Cepeda, Tomás Vázquez, Juan de Acosta, Lic. De la Gama, Gabriel de Rojas, Martín Pizarro, Garcilaso, Diego Maldonado, entre 54 firmas más.

${ }^{30}$ Carta de los principales del Perú a La Gasca, 14 de octubre de 1546, en Pérez de Tudela, Documentos relativos, 1: 369. Énfasis agregado.

${ }^{31}$ Carta de Gonzalo Pizarro a los oidores de la Audiencia de Lima, 3 de agosto de 1544, ibídem, 2: 193.
} 
no se nos haga fuerza, y que nos conservemos en justicia, y que lo que $\mathrm{Su}$ Majestad mandare conforme a derecho, se cumpla, pues nadie quiere que se le haga agravio ${ }^{32}$.

Si bien se reconocía que los encomenderos no tenían derecho de propiedad sobre sus indios, ya que el Rey era el señor directo de todas las encomiendas, estaba dispuesto que a ningún encomendero se le podían quitar sus indios sin ser primero "oydos y vencidos por derecho", y por delito "que tenga perdimiento de bienes",33.

Al mismo tiempo, no debemos dejar de mencionar los problemas que traía la coexistencia de leyes y disposiciones superpuestas que conformaban el sistema legal. Esto se debía a que una ley posterior no derogaba una anterior, así que todas quedaban vigentes. Esto traía como consecuencia que en cada litigio, si bien existía un orden de prelación ${ }^{34}$, cada parte podía recurrir a aquella disposición que más conviniera a sus intereses. El hecho de que estas leyes rigieran acumulativamente permitió que los pizarristas defendieran sus intereses recurriendo a aquella legislación que los facultara a desafiar los dictados de la autoridad real.

Respecto al derecho vigente en América, debemos destacar no solo la permanencia del derecho castellano como "modelo inspirador" y como legislación aplicable, sino también al "Derecho común, como saber de juristas; el Derecho natural, como orden indisponible; el Derecho canónico; el Derecho indiano", como derecho español formulado para América ${ }^{35}$. A su vez, hay que aclarar que las Partidas (ubicadas en último lugar en el ordenamiento del derecho castellano, y vigentes en las Indias como derecho supletorio) alcanzaron en América un papel predominante en la práctica legal de estos territorios como código regulador de las instituciones de derecho privado ${ }^{36}$. Así:

El espíritu de la vieja Edad Media, ya superado o en trance de superación en la Metrópoli [...], resurgió en las capitulaciones de descubrimiento y

\footnotetext{
${ }_{32}^{32}$ Carta de Gonzalo Pizarro al virrey, 2 de agosto de 1544, ibídem, 2: 202.

${ }^{33}$ Ots Capdequí, El Estado español, 150.

${ }^{34}$ En el derecho castellano, el orden de prelación era el siguiente: Ordenamiento de Alcalá, Fuero Municipal (vigente según cada ciudad), Fuero Real y las Siete Partidas. Ots Capdequí, El Estado español, 1975. Este orden se mantuvo durante toda la Edad Moderna y las leyes que se iban agregando iban ocupando el primer lugar en la lista anterior, como ocurrió con las Leyes de Toro (1505), La Nueva Recopilación (1567) y la Novísima Recopilación (1805).

${ }^{35}$ El Derecho indiano rigió en América desde la época de conquista y descubrimiento hasta la segunda mitad del siglo XIX. Víctor Tau Anzoátegui, Nuevos horizontes en el estudio histórico del derecho indiano (Buenos Aires: Instituto de Investigaciones de Historia del Derecho, 1997).

${ }^{36}$ Ots Capdequí, El Estado español.
} 
nueva población, condicionando la vida jurídica, social y económica de los nuevos territorios, con fuertes resabios señoriales ${ }^{37}$.

De esta manera, entendemos que debe haber sido realmente difícil borrar concepciones tan asentadas desde hace tantos años. Teniendo esto presente, los reclamos pizarristas adquieren otro sentido y hacen difícil reducirlos a meras estrategias jurídicas utilizadas con el solo fin de bloquear la legislación real.

Nosotros, ¿en qué habemos de deservido a Su Majestad?, ¿en qué le habemos sido tan traidores o en qué habemos pecado tan gravemente, que no merezcamos ser oídos, y que interponiendo una suplicación tan justa como se ha interpuesto por todo este reino, de las ordenanzas que $\mathrm{Su}$ Majestad nos invía, por ser como son, si se executase, total destruición de todo él, el cual con tanto trabaxo, tanto gasto de nuestras haciendas, riesgos de nuestras vidas, sangre nuestra e pérdida de nuestros debdos y amigos, sin costa alguna de Su Majestad habemos ganado, nos sea denegada e no admitida, y que mientras mas se suplique y mas razones y causas se den para que se admita, más asperamente e con más rigor se executen las dichas ordenanzas, no como en ellas se contiene, sino en peor sentido en nuestro daño y en el deste reino? [...] Viendo una cosa tan áspera, viendo una cosa tan recia, los vecinos y cabildos de las ciudades de acá, ya que se les deniega la defensa que derecho tienen, y el príncipe de justicia no le puede quitar $[\ldots]^{38}$.

A su vez, es importante destacar el papel que jugaba la costumbre dentro del orden jurídico bajomedieval. Víctor Tau Anzoátegui, en un interesante análisis acerca del poder de la costumbre en el derecho castellano e indiano, demuestra que la misma se hallaba fuertemente arraigada en el orden jurídico hasta bien entrado el siglo XVIII. De esta manera, la costumbre y la ley eran separadas por una línea muy delgada, llegando la primera en ocasiones a ser considerada como la ley misma. A pesar de que la conformación de un sistema legislativo para todo el reino a partir de la formulación del Ordenamiento de Alcalá (1348) implicaba un desplazamiento de la costumbre del ámbito jurídico, lo cierto fue que la misma continuó siendo admitida para la resolución de situaciones especiales y aceptada en las Siete Partidas $^{39}$. La formulación de un ordenamiento legal iba de la mano con la fuerte

37 Ots Capdequí, en Ruggiero Romano, "Entre encomienda castellana y encomienda indiana: una vez más el problema del feudalismo americano (siglos XVI-XVII)", Anuario IEHS (Tandil, Argentina), 3 (1988): 37. Énfasis en el original.

${ }^{38}$ Carta de Gonzalo Pizarro a los oidores de la Audiencia de Lima, 3 de agosto de 1544, en Pérez de Tudela, Documentos relativos, 195. Énfasis agregados.

${ }^{39}$ En ellas se definía a la costumbre como "el derecho no escrito usado por los hombres durante largo tiempo". Víctor Tau Anzoátegui, El poder de la costumbre. Estudios sobre el 
tendencia legalista que empezaba a gestarse en España con el claro fin de fortalecer el poder real a través de una unificación política y jurídica que relegara las particularidades locales. Esto último queda francamente demostrado con la sanción de las Leyes Nuevas. Es así como "los únicos límites al poder real lo constituyeron entonces el respeto a los derechos divino y natural y a las leyes fundamentales del reino" ${ }^{, 40}$.

Continuando con los planteos de dicho autor, la costumbre se convirtió en un instrumento jurídico muy utilizado en ciertas ciudades del Nuevo Mundo durante los siglos XVI y XVII, ya que era una herramienta que permitía enfrentar los designios reales. Todo esto no debe dejar de enmarcarse en el contexto peruano del siglo XVI, donde permanecía vigente la noción de coparticipación legislativa entre pueblo y rey y donde era frecuente recurrir a la "antigua costumbre" en la apelación de distintos casos. En la representación de Gonzalo Pizarro al rey se deja entrever esta persistencia de la costumbre como recurso legal: "Vuestra alteza no puede de derecho hacer ni promulgar ley que ponga pena en lo pasado que no era delito, ni contra buenas costumbres, ni prohibido en derecho" ${ }^{41}$. Siguiendo el lema "Se acata, pero no se cumple", los perjudicados con las nuevas leyes sostenían que:

[...] siendo como son las dichas ordenanzas tan en nuestro perjuicio, y estando proveído por la ley real que cuando ansí vuestra alteza proveyese alguna cosa que sea en perjuicio o tocante alguno, que lo que ansí proveyese se suspenda su execusión hasta se lo hacer saber, y que lo tal sea obedecido y no cumplido $[\ldots]^{42}$.

Cabe aclarar que esta medida no era tomada como un acto de desobediencia, pues simplemente con ella se pretendía poner al tanto al rey de lo acontecido y que este, con la nueva información recibida, resolviese en forma definitiva ${ }^{43}$. Sumado a esto, para los insurrectos el rey no podía dejar de reconocer el gran esfuerzo por los servicios prestados en la conquista, ya que la Corona poseía tales territorios gracias al esfuerzo físico y económico de los conquistadores. Decían los oficiales (gobernadores, presidentes, oidores, etc.) agraviados por las ordenanzas:

Nosotros ganamos este Imperio a nuestra costa y riesgo, y aumentamos la corona de Castilla con tan grandes reinos y señoríos como hoy tiene. En

derecho consuetudinario en América hispana hasta la emancipación (Buenos Aires: Instituto de Investigaciones de Historia del Derecho, 2001), caps. 3-4: 107.

${ }^{40}$ Ibídem, 93.

${ }^{41}$ Pérez de Tudela Bueso, Documentos relativos, 2: 387. Énfasis agregado.

${ }^{42}$ Ibídem, 394. Énfasis agregado.

${ }^{43}$ La facultad de las autoridades coloniales de suspender la aplicación de las ordenanzas reales que iban en su perjuicio se reconoció legalmente en la Recopilación de 1680. Ots Capdequí, El Estado español. 
pago de estos servicios nos dieron los indios que poseemos, y nos los dieron por dos vidas, haviendo de ser perpetuos, como los señoríos de España. La causa por que nos los quitan ahora es porque nos eligieron para oficiales de la hazienda real, para ministros de la justicia y regidores de los pueblos. Si los tales oficios los administramos bien, y no hizimos agravio a nadie, ¿qué razón hay que por haver sido elegidos por hombres de bien nos quiten nuestros indios y manden que nos quedemos con los oficios, que es achaque para quitarnos otro día lo que ganaremos adelante? Para venir a parar en esto, mejor nos fuera haver sido ladrones, salteadores, adúlteros, homicidas, pues las ordenanzas no hablan con ellos, sino con los que hemos sido hombres de bien ${ }^{44}$.

Queda claramente planteada aquí la persistencia de representaciones medievales sobre las prerrogativas con las que debían beneficiarse quienes hubieran prestado servicios a la Corona. Claro está que Gonzalo y su gente no solo luchaban por defender aquellos beneficios ganados, sino también por la conservación del poder que detentaban estas minorías locales, hecho que se extenderá durante todo el período colonial.

\section{Pretensión de gobernar el Perú}

En la rebelión de Gonzalo Pizarro podemos observar la presencia de dos objetivos que se entrelazan entre sí. Por un lado, como se ha señalado anteriormente, existía la imperante necesidad de los conquistadores y encomenderos de bloquear una legislación que creían seriamente nociva para sus intereses económicos y políticos. Por otro lado, podemos observar como la rebelión pizarrista se convierte en el marco propicio para que su líder pudiera acceder a la tan preciada gobernación que por tantos años le había sido negada. Recordemos que su hermano Francisco lo había nombrado en su testamento como su sucesor gracias a un poder concedido por la misma Corona. El hecho de que Vaca de Castro ocupara este cargo por orden del rey frustraba las ambiciones del joven Pizarro. La contienda producida por la instauración de las Leyes Nuevas le brindaba a nuestro hombre la ocasión ideal no solo de defender sus intereses económicos sino también de alcanzar sus objetivos políticos.

Lo que deseamos dejar planteado aquí es que, si bien Gonzalo podía estar impulsado por su propia ambición estaba, al mismo tiempo, encarnando los objetivos colectivos. Si en un primer momento Pizarro dudó en responder favorablemente a las demandas que le hacían los principales del Perú para que los representara, fue posiblemente porque veía en los pedidos de los vecinos el interés de servirse de él para lograr la revocación de las ordenanzas y porque, una vez

${ }^{44}$ Garcilaso de la Vega, Historia General del Perú, 3 y 4: 17. 
logrado esto, retirarían su apoyo a la causa pizarrista. Si Gonzalo pensó en esta posibilidad, no se equivocó. Aún así, decidió enfrentar el desafío posiblemente considerando que esta sería una oportunidad irrepetible para disputar la gobernación.

Ahora bien, una vez enviados los procuradores a España para hacer llegar al rey los motivos de la revuelta, y mientras se esperaba la confirmación del cargo de gobernador para Gonzalo Pizarro, se hizo imperante la necesidad de legitimar, por medio de una serie de recursos jurídicos, la situación del régimen. En esta situación de crisis en la que se encontraba la sociedad hispanoperuana, en parte provocada por la instauración de las nuevas ordenanzas y en parte por la rudeza que el virrey utilizó al aplicarlas, se debilitó el incipiente orden institucional y se generó el ambiente propicio para el surgimiento de un líder o caudillo que gobernaría hasta que "Su Majestad otra cosa mandase". Sin embargo, el rey nunca reconoció el título de gobernador para Gonzalo Pizarro y esto hizo que su régimen tuviera una fuerte carga de ilegalidad.

Lohmann Villena concluye que la dominación pizarrista estaba desprovista de origen legítimo y carecía de validez jurídica, por lo tanto, ni las autoridades ni el pueblo estaban obligados a reconocerla. La concibe como un régimen legalmente inexistente, ya que los argumentos jurídicos implementados para justificar la viabilidad de su régimen eran demasiado frágiles ${ }^{45}$. Sin embargo, entendemos que la rebelión tuvo un alto nivel de acatamiento y tanto líder como seguidores se hallaban convencidos de la legitimidad de sus actos y los consideraban lícitos bajo las normas jurídicas vigentes. Ahora analizaremos los argumentos jurídicos apelados por los ideólogos del movimiento pizarrista y, a partir de la lectura del trabajo de Lohmann Villena ${ }^{46}$ acerca de las ideas jurídico-políticas que entraron en juego en la rebelión de Gonzalo Pizarro, expondremos cuáles fueron los recursos legales utilizados por los pizarristas para legitimar su gobierno.

El primero de los argumentos que surgió entre los ideólogos del movimiento fue el derecho de sucesión. La Corona había concedido a Francisco Pizarro - por medio de una provisión real firmada en septiembre del 1534 y ratificada en noviembre de $1536{ }^{-47}$ el derecho a nombrar un sucesor y él había nombrado a Gonzalo como la persona que debería asumir la gobernación temporal hasta que su propio hijo alcanzara la edad para ello. En el caso de que el sucesor muriese antes que su

\footnotetext{
${ }^{45}$ Lohmann, Las ideas jurídico políticas.

${ }^{46}$ Ibídem.

47 "Yo vos ruego y encargo que cuando dios fuere servido de llevaros desta presente vida nombreys en vuestro lugar persona cual convenga A nuestro servicio y a la execusion de la nuestra justicia y buena gobernación desa tierra e de quienes vos tengais confianza que hara lo que debe como de vos confio", Porras, Cedulario del Perú, 53-54.
} 
progenitor, Gonzalo asumiría el cargo como titular ${ }^{48}$. Sin embargo, el rey hizo omisión de ello y nombró en su lugar a Cristóbal Vaca de Castro con plenitud de poderes. Era necesario, a fin de reforzar el dominio de la Corona, frenar el creciente poder que se gestaba en torno al linaje pizarrista, cada vez más poderoso económica y políticamente. La necesidad de refrenar la potencial autonomía de estos centros de poder locales se logró estableciendo un sistema político basado en una mayor presencia del Estado con la fundación en 1543 del Virreinato del Perú y la creación de la Audiencia de Lima. Frente a la negativa del rey a confirmar el cargo de gobernador a Gonzalo, este último recrimina lo siguiente:

En no saber en qué ha pecado tanto, o qué crimen contra Vuestra Majestad ha cometido, que las mercedes que Vuestra Majestad le ha hecho, debiéndole hacer otras mayores, pues siempre le sirve, agora se las renueva, y en algunas cosas Vuestra Majestad se olvide de su palabra real que dio a los conquistadores, en las capitulaciones que hizo con el marqués mi hermano, y que como a hombres criminosos y fementidos, aquella se les quebrantase en remuneración destos servicios y del que yo he hecho en gastar toda mi hacienda para que este reino no se destruyese ${ }^{49}$.

Como vemos en esta cita, la Corona desarticulaba todo intento de legitimar la gobernación de Gonzalo Pizarro por medio del recurso al derecho de sucesión. Otro de los medios para dotar de legalidad al régimen pizarrista salió a la luz a través de rumores que se echaban a correr desde la hueste pizarrista de casar al joven Pizarro con una princesa inca para crear una casa real peruana por medio de la unión de la familia real incaica con la del primer conquistador. Probablemente el objetivo consistía en dotar al nuevo miembro de la legitimidad proveniente de la nobleza incaica, por un lado, y del linaje del primer conquistador, por el otro. Sin embargo, tal rumor no fue más que eso y rápidamente se desecha al leer las cartas de Gonzalo, donde sostiene que "por agora no me pienso casar sino con buenas lanzas y caballos, porque con esto hemos de pasar agora tiempo" ${ }^{90}$.

Además, frente al informe que había llegado a oídos del rey acerca del posible enlace de Gonzalo con su sobrina doña Francisca Pizarrro Yupanqui, hija del marqués, se envía orden a La Gasca para que lo evitara. En una relación de La Gasca al Consejo de Indias, desmiente tal murmuración, afirmando que:

\footnotetext{
${ }^{48}$ Cabe aclarar que la Corona continuaba manteniendo la facultad de nombrar a quien creyera conveniente, admitiendo al sucesor de Pizarro solamente de manera provisional y como interino.

${ }^{49}$ Carta de Gonzalo Pizarro al Emperador, en Pérez de Tudela, Documentos relativos, 1: 364.

${ }^{50}$ Carta de Gonzalo Pizarro a Alonso de Alvarado, 17 de octubre de 1547, ibídem, 2: 167.
} 
[...] nunca a él [Pizarro] le pasó por pensamiento, ni había para que pasarle, porque este casamiento, ni con los españoles, ni con los naturales, le autorizaba, ni hacía parte para su rebelión, porque las mujeres entre estos naturales nunca heredan ni hacen dellas caso, especialmente ésta [Francisca], que viene ya por tantas quiebras ${ }^{51}$.

Pizarro y su entorno personal sabían del arbitrio que reconocía que un buen gobierno y la extensión en el tiempo del mismo podían finalizar en un reconocimiento, no solo de hecho, sino también de derecho, gozando así de la preciada legitimidad. En ejercicio de su papel de gobernador, puede decirse que, una vez en su cargo, Gonzalo procuró mantener el orden público, cumplir las leyes, controlar las rentas fiscales ${ }^{52}$ y mantener pacíficas estas tierras pretendiendo lograr, en la medida de las posibilidades, la voluntad general. Además, Garcilaso comenta:

Mandó con provisiones que no cargassen indios, que era una de las ordenanças, ni rancheasen, [...] so pena de muerte. [...] Procuró mucho el quinto y hazienda del Rey, diciendo de que assí lo hazía su hermano Francisco Piçarro.[...] y que, pues ya no havía guerra, muerto Blasco Nuñez, que sirviessen todos al rey, por que revocase las ordenanças, confirmasse los repartimientos y les perdonasse lo pasado. Todos entonces loavan su governación, y aún Gasca dixo, después que vió los mandamientos, que governaba bien para ser tirano ${ }^{53}$.

Posiblemente estos argumentos reposaban en el recurso legal que brindaban las Partidas, donde se observa que una de las formas por la cual se gana el señorío de un reino era por conformidad de todos los del reino que lo escogieran por señor ${ }^{54}$. Así, los principales del Perú, en una carta a La Gasca, suplican que:

Su Majestad confirme la gobernación destos reinos a Gonzalo Pizarro, porque con él toda la tierra estará segura y pacífica en servicio de Su Majestad y en toda justicia, enviándole en cada un año sus dineros y quintos reales, por que él, por sus virtudes es muy amado de todos, $\mathrm{y}$ tenido

${ }^{51}$ Relación de La Gasca al Consejo de Indias, 26 de septiembre de 1558, ibídem, 2: 275.

${ }^{52}$ A pesar de que procuró recaudar fondos para la Corona, Gonzalo y su gente debieron echar mano de los fondos fiscales para sustentar la rebelión en sus últimos momentos.

${ }^{53}$ Es preciso mencionar que Garcilaso mantiene una destacada postura propizarrista en toda su obra, lo cual implica que tomemos sus aseveraciones con mucho cuidado. Sin embargo, no podemos dejar de reconocer los importantes aportes que brinda a este tema. Inca Garcilaso de la Vega, Historia General del Perú, 4: 119-120.

${ }^{54}$ Al mismo tiempo, se aclara: "non habiendo pariente que deva heredar su señorío del rey finado por Derecho". "Código de las Siete Partidas del Rey Alfonso El Sabio", en Los códigos españoles, t. 2 (Madrid: Imprenta de la Publicidad, 1848), lib. 2, título 1, ley 9. 328. 
por padre de la tierra, y con la larga experiencia que tiene en esta tierra, entiende lo que se debe hacer y conviene a la gobernación destos reinos, y lo hace con mucha facilidad, lo que otro que él no fuese no lo podría hacer $\sin$ haber la tierra rescebido gran daño cuando lo viniere a entender ${ }^{55}$.

Frente a la cantidad de reclamos que se hicieron desde las colonias ultramarinas al rey Carlos V en orden de disolver las nuevas ordenanzas, en octubre de 1545 fueron revocadas las disposiciones más irritantes a los intereses de los encomenderos, como, por ejemplo, la Ley 30 y aquella que quitaba las encomiendas a aquellos que habían participado de las guerras entre pizarristas y almagristas. Sin duda, eran los capítulos que más habían causado el descontento entre los conquistadores. Frente a esta medida, Lohmann Villena aduce que se desvanecían las causas motrices de la rebelión al quedar sin efecto las ordenanzas más irritantes. Sin embargo, entendemos que, aunque Gonzalo Pizarro se convirtió en el portavoz de los principales del Perú para pedir por la revocación de las mismas, también estaba en juego para nuestro hombre el anhelo de suceder a su hermano en la gobernación, facultad por la cual creía estar autorizado gracias al propio testamento de su hermano, el marqués. Es cierto que los encomenderos creyeron hallar en Gonzalo al hombre ideal para que representara sus intereses y llevara a cabo sus demandas, pero cierto es también que el líder pizarrista supo aprovechar la ocasión con total astucia como contienda propicia para apelar a la gobernación por la cual se reconocía justo heredero. Por lo tanto, sugerimos aquí que los objetivos, por lo menos los de Pizarro, no habían cambiado tanto desde los inicios de la rebelión.

Es indiscutible que después del magnicidio del virrey la situación legal de los rebeldes no era buena. Para justificar tal acto, se elaboró una probanza en noviembre de 1546 con el fin de testimoniar que el virrey había sido un factor de alteración del orden público y, por ende, el accionar de Pizarro y sus hombres, respaldado por una disposición de la Audiencia, se había desarrollado dentro del marco legal y con el fin de restablecer la tranquilidad pública ${ }^{56}$. Por su parte, Gonzalo Pizarro explica las causas de la alteración frente al Virrey Núñez Vela, de la siguiente manera:

La causa que hemos tenido para esta alteración, es sola la que vuestra señoría nos ha dado entrando solo en este reino, sin los señores oidores, [...] y no admitiendo exebcion ni causa legítima a ninguna de las personas a quien tocaba, procediendo sin orden de derecho, por sola voluntad, y lo que peor y que mas nos exaspera, no admitiendo suplicación alguna que

\footnotetext{
${ }^{55}$ Carta de los principales del Perú a Gasca, 14 de octubre de 1546, en Pérez de Tudela, Documentos relativos, 1: 369-170.

${ }^{56}$ Lohmann, Las ideas jurídico políticas.
} 
para ante Su Majestad se haya interpuesto por los cabildos y vecinos de las ciudades de San Miguel, Trujillo y los Reyes, antes denegándolas y procediendo de hecho a executar aquello de que tan justa y santamente suplicaba, seyendo, como es de derecho natural y que el príncipe no lo puede quitar ni admover ${ }^{57}$.

Finalmente, y como último intento de legitimar la empresa, a mediados de 1546 se elige una serie de procuradores que expondrían al rey las demandas de los pizarristas. La misión recayó en Hernando Pizarro (quien ya estaba en España), el capitán Lorenzo de Aldana y Gómez de Solís (maestresala de Gonzalo). Con tal fin, se destacaba la labor de Gonzalo como uno de los primeros conquistadores de estos reinos y, por lo tanto, experimentado en estas tierras, que conocía bien a su gente, protegía a los naturales y, básicamente, detentaba el poder según el derecho sucesorio pactado entre su hermano, el marqués, y la Corona ${ }^{58}$. Así, Gonzalo nunca perdió las esperanzas de hacer oír sus demandas y finalmente ser reconocido en su puesto por el monarca. A pesar de ello, la demanda nunca llegó a manos del rey, ya que, una vez en Panamá, los procuradores se sumaron a las huestes de La Gasca y convencieron a Pedro de Hinojosa, con lo cual la armada pizarrista pasaba ahora al poder del enviado regio.

Por aquel entonces comenzaban a correr rumores en la hueste y principalmente en el entorno más cercano a Gonzalo Pizarro sobre la posible coronación de este último como rey del Perú. Probablemente se trataba solo de la intención de algunos de los más allegados al caudillo, que deseaban con gran anhelo ver a su líder coronado, ideas que muy posiblemente a Gonzalo le gustaba escuchar, pero que por el momento no estaba en sus planes llevar a cabo. Además, Lorandi ${ }^{59}$ sostiene que el romper vínculos con la Metrópoli era bastante arriesgado para la colonia, ya que se encontraba aún fuertemente vinculada a ella por cadenas comerciales, además que España continuaba siendo el país con el cual se identificaban y cuyo modelo deseaban reproducir en estas tierras.

Lohmann Villena destaca en su obra que el deseo de legitimar su gobierno hizo que los ideólogos del movimiento pensaran, como una de las alternativas, en obtener el reconocimiento del papa. Este proyecto estaba inspirado en la tradición jurídicocanónica que sostenía que el papa podía instituir, confirmar y coronar reyes. Las Partidas también hacen alusión a esto cuando se refieren a que el rey podía obtener el señorío de un reino por medio del consentimiento del papa ${ }^{60}$. Por lo tanto, se

\footnotetext{
${ }^{57}$ Carta de Gonzalo Pizarro al virrey, 2 de agosto de 1544, en Pérez de Tudela, Documentos relativos, 2: 201.

${ }^{58}$ Entre estos planteos también se encontraba el pedido de los insurrectos para que no se instalase la Audiencia en el Perú durante dos períodos.

${ }^{59}$ Lorandi, Ni ley, ni rey.

60 "Código de las Siete Partidas", las Partidas I, II, IX.
} 
pretendía que Pizarro fuera reconocido como rey por la máxima autoridad católica. Para llevar esto a cabo, se debía hacer de Perú un país feudatario del sumo pontífice y renunciar a los vínculos de vasallaje con la Corona de Castilla. Sin embargo, tal oferta nunca llegó a oídos del papa, ya que Sebastián de los Ríos, a quien se le había encomendado la misión, fue detenido en Quito, truncando así su viaje a Roma. Otra comisión a cargo de Fray Tomás de San Martín (regente de los dominicos) y Fray Martín de Calatayud (obispo de Santa Marta) tampoco logró su cometido, pues, ya en Panamá, los clérigos también se sumaron al bando de La Gasca. Como se dijo anteriormente, Gonzalo nunca manifestó de manera explícita intenciones de romper vínculos de vasallaje con el rey. Según Garcilaso:

El respeto natural que a su Príncipe tenía pudo en él más que la persuasión de sus amigos; y también porque nunca perdió la esperança de que la Majestad Imperial le haría merced de confirmarle la governación del Perú ${ }^{61}$.

Es así como aquí entra en juego una contradicción interna de la rebelión, que muestra que, a pesar de la constante aclamación por parte de sus más fervientes seguidores para ver a su líder coronado, Gonzalo nunca dejó de remarcar su condición de servidor del rey. En las cartas que hemos tenido oportunidad de leer, observamos que nuestro hombre remarca permanentemente su condición de vasallo que no pretende más que servirle. Esto nos puede hacer pensar que Gonzalo no se encontraba ante una disyuntiva entre su lealtad al emperador y la necesidad de defender sus intereses económicos y políticos; por el contrario, estaba convencido de que aquellos derechos a los cuales apelaba los había ganado justamente y que el reclamo por los mismos no implicaba necesariamente una desvinculación del vasallaje con el monarca. Lo mismo puede decirse respecto a su deseo de gobernar el Perú, tal como lo había hecho su hermano. A juicio de Gonzalo, era perfectamente viable ser gobernador y al mismo tiempo ser leal a su rey. Evidentemente, la Corona no pensaba lo mismo, más aun si recordamos el destacado interés que tenía por limitar el poder (económico y político) de los vecinos del Perú, sobre todo del linaje pizarrista.

En síntesis, como objetivo general de este trabajo, se demostró la permanencia de concepciones típicamente medievales que perduraron y se reafirmaron en la práctica jurídica y política desarrollada en el Perú, en marcada disconformidad con el avance de las ideas de la modernidad que se gestaban en la Metrópoli. Nuestro interés residió así en destacar la sujeción de estas representaciones por parte de los conquistadores y primeros encomenderos a partir de enmarcar tales costumbres dentro de una sociedad en transición y en constante adaptación, como lo fue la sociedad hispanoperuana del siglo XVI. La rebelión de Gonzalo Pizarro

${ }^{61}$ Garcilaso, Historia General del Perú, lib. 4:137. 
ejemplifica claramente la pugna entre dos modelos políticos (uno bien arraigado en la conciencia general y otro con intenciones de desplazarlo), que generó un clima de confusión política y desorden. Es por ello que no debemos encasillar las acciones de Gonzalo y su gente dentro de esquemas que solo los ven como desleales a la Corona; más bien, es preciso contextualizar sus acciones y formas de pensar dentro de esta sociedad cambiante, en cuyos imaginario colectivo y aparato jurídico convivían paradigmas propios de la baja Edad Media, y ver que solo recién comenzaban a perfilarse de manera embrionaria los primeros indicios de la modernidad en América.

\section{Bibliografía}

Arciniega, Rosa. Dos rebeldes españoles en el Perú. Gonzalo Pizarro y Lope de Aguirre. Buenos Aires: Sudamericana, 1946.

Bataillon, Marcel. "Interés hispánico en el movimiento pizarrista". En La Colonia, ensayos peruanistas, comp. Alberto Tauro. 1962; reimpresión, Lima: Universidad Mayor de San Marcos, 1995.

"Los colonos del Perú contra Carlos V. Análisis del movimiento pizarrista (1544-1548)". En La Colonia, ensayos peruanistas, comp. Alberto Tauro. 1962; reimpresión, Lima: Universidad Mayor de San Marcos, 1995.

Cieza de León, Pedro. Crónica del Perú. Vol. 3, t. 2, parte 4. [1553]; Lima: Pontificia Universidad Católica del Perú, 1991-1994.

"Código de las Siete Partidas del Rey Alfonso El Sabio". En Los códigos españoles. T. II. Madrid: Imprenta de la Publicidad, 1848.

Durand, José. La transformación social del conquistador. Lima: Nuevos Rumbos, 1958.

Fernández de Palencia, Diego. "Primera y segunda parte de la Historia del Perú". En Crónicas del Perú, ed. Juan Pérez de Tudela Bueso. Serie Biblioteca de Autores Españoles. T. 164-168. [1568]; Madrid: Atlas, 1963.

Garcilaso de la Vega, Inca. Historia General del Perú. Segunda parte de los comentarios reales de los Incas. [1617]; Buenos Aires: Emecé, 1944.

Gutiérrez de Santa Clara, Pedro. "Quinquenarios o Historia de las guerras civiles del Perú". En: Crónicas del Perú, ed. Juan Pérez de Tudela Bueso. T. II. 
Serie Biblioteca de Autores Españoles. T. 165. [1600]; Madrid: Atlas, 1963.

Lavallé, Bernard. Francisco Pizarro. Conquistador de l'extrême. París: Payot, 2004.

Lempérière, Annik. "La representación política en el Imperio Español a finales del Antiguo Régimen. Dinámicas de Antiguo Régimen y orden constitucional". Representación, justicia y administración en Iberoamérica. Siglos XVIII-XIX, coord. Marco Bellingeri. Turín, Italia: Otto Editore, 2000.

Levillier, Roberto, dir. Gobernantes del Perú. 2 t. Madrid: Sucesores de Rivadeneyra, 1921.

Lockhart, James. Los de Cajamarca. Un estudio social y biográfico de los primeros conquistadores del Perú. 2 t. Lima: Milla Batres, 1986.

El mundo hispano peruano. 1532-1560. México: Fondo de Cultura Económica, 1982.

Lohmann Villena, Guillermo. Las ideas jurídico políticas en la rebelión de Gonzalo Pizarro. La tramoya doctrinal del levantamiento contra las Leyes Nuevas en el Perú. Valladolid: Casa-Museo de Colón y Seminario Americanista; Universidad de Valladolid, 1977.

Lorandi, Ana María. Ni ley, ni rey ni hombre virtuoso. Guerra y sociedad en el virreinato del Perú, siglos XVI y XVII. Barcelona: Gedisa, 2002.

Loredo, Rafael. "Relaciones de repartimientos que existían en el Perú al finalizar la rebelión de Gonzalo Pizarro". Revista de la Universidad Católica del Perú (Lima), 8, núm. 1 (1940): 51-62.

“Alardes y derramas". Revista Histórica (Lima), 14 (1941): 319-324

Monsalvo Antón, José María. La baja Edad Media en los siglos XIV-XV. Política y cultura. Caps. 3 y 7. España: Síntesis, 2000.

Ots Capdequí, J. M. El Estado español en las Indias, ed. Juan Pérez de Tudela Bueso. México: Fondo de Cultura Económica, 1975. 
Pérez de Tudela Bueso, Juan, ed. "Observaciones generales sobre las guerras civiles del Perú". Crónicas del Perú. Serie Biblioteca de Autores Españoles. T. 164. Madrid: Ediciones Atlas; 1963.

. Documentos relativos a Don Pedro de La Gasca y a Gonzalo Pizarro. T. 21, vols. 1 y 2. Madrid: Archivo Documental Español; Real Academia de la Historia, 1964.

Pietschmann, Horst. "Los principios rectores de organización estatal en las Indias". En Inventando la Nación. Iberoamérica. Siglo XIX. A. Annino y FrançoisXavier Guerra. México: Fondo de Cultura Económica, 2003.

Porras Barrenechea, Raúl. Cedulario del Perú. Siglos XVI, XVII y XVIII. Lima: Ministerio de Relaciones Exteriores del Perú, 1944-1948.

Romano, Ruggiero. "Entre encomienda castellana y encomienda indiana: una vez más el problema del feudalismo americano (siglos XVI-XVII)". Anuario IEHS (Tandil, Argentina), 3 (1988).

Tau Anzoátegui, Víctor. Nuevos horizontes en el estudio histórico del derecho indiano. Buenos Aires: Instituto de Investigaciones de Historia del Derecho, 1977.

. El poder de la costumbre. Estudios sobre el derecho consuetudinario en América hispana hasta la emancipación. Buenos Aires: Instituto de Investigaciones de Historia del Derecho, 2001.

Varón Gabai, Rafael. La ilusión de poder. Apogeo y decadencia de los Pizarro en la conquista del Perú. Perú: Instituto de Estudios Peruanos; Instituto Francés de Estudios Andinos, 1996.

Varón Gabai, Rafael y Auke Pieter Jacobs. "Los dueños del Perú: Negocios e inversiones de los Pizarro en el siglo XVI". Histórica (Lima), 2 (1989): 197-242.

Zarate, Agustín. Historia del descubrimiento y conquista del Perú. Edición, notas y estudio preliminar de Franklin Pesase G. Y. y Teodoro Hampe Martínez. [1555]; Lima, Pontificia Universidad Católica del Perú, 1995.

Fecha de recepción: 17 de febrero de 2006.

Fecha de aprobación: 14 de junio de 2006. 